\title{
Carbamazepine Measurement
}

National Cancer Institute

\section{Source}

National Cancer Institute. Carbamazepine Measurement. NCI Thesaurus. Code C147322.

The determination of the amount of carbamazepine present in a sample. 